\title{
C16-ceramide and sphingosine 1-phosphate/S1PR2 have opposite effects on cell growth through mTOR signaling pathway regulation
}

\author{
MIN HEE KIM ${ }^{1 *}$, JOO-WON PARK ${ }^{2 *}$, EUN-JI LEE ${ }^{1}$, SHIN KIM $^{3}$, SUN-HYE SHIN ${ }^{2}$, JUNG-HYUCK AHN ${ }^{2}$, \\ YUNJAE JUNG ${ }^{4,5}$, INKEUN PARK ${ }^{6}$ and WOO-JAE PARK ${ }^{1,5}$ \\ ${ }^{1}$ Department of Biochemistry, College of Medicine, Gachon University, Incheon 21999; ${ }^{2}$ Department of Biochemistry, \\ College of Medicine, Ewha Womans University, Seoul 07985; ${ }^{3}$ Department of Immunology, School of Medicine, \\ Keimyung University, Daegu 42601; ${ }^{4}$ Department of Microbiology, College of Medicine, Gachon University; \\ ${ }^{5}$ Department of Health Sciences and Technology, GAIHST, Gachon University, Incheon 21999; \\ ${ }^{6}$ Division of Medical Oncology, Department of Internal Medicine, Gachon University \\ Gil Medical Center, Incheon 21565, Republic of Korea
}

Received March 27, 2018; Accepted July 19, 2018

DOI: $10.3892 /$ or.2018.6689

\begin{abstract}
Recently, sphingolipid derivatives, such as ceramide and sphingosine-1-phosphate (S1P), have emerged as key modulators in apoptotic cell death and cell proliferation. This study aimed to clarify the underlying signaling pathways of ceramide and S1P involved in breast cancer cell proliferation. Ceramide acyl chain length is determined by six mammalian ceramide synthases (CerS). We overexpressed CerS1 to 6 in MCF-7 cells to examine whether ceramide signaling propagation varies as a function of acyl chain length. Among the six CerS, only CerS6 overexpression reduced phosphorylation of Akt, S6 kinase (S6K), and extracellular signal-regulated kinases (ERK) as shown by western blotting. In addition, CerS6 overexpression reduced MCF-7 cell proliferation. This effect was partially reversed by co-treatment with MHY1485,
\end{abstract}

Correspondence to: Professor Woo-Jae Park, Department of Biochemistry, College of Medicine, Gachon University, 155 Gaetberllo, Incheon 21999, Republic of Korea

E-mail: ooze@gachon.ac.kr

Professor Inkeun Park, Division of Medical Oncology, Department of Internal Medicine, Gachon University Gil Medical Center, 774 Namdongdaelo, Incheon 21565, Republic of Korea

E-mail: ingni79@hanmail.net

*Contributed equally

Abbreviations: CerS, ceramide synthase; ERK, extracellular signal-regulated kinases; mTOR, mammalian target of rapamycin; SL, sphingolipid; Sphk, sphingosine kinase; S1P, sphingosine1-phosphate; S1PR, sphingosine-1-phosphate receptor; S6K, p70 S6 kinase

Key words: mTOR signaling, breast cancer, ceramide synthase, sphingosine-1-phosphate, sphingosine-1-phosphate receptor an activator of mammalian target of rapamycin (mTOR), demonstrating an important role for the mTOR pathway in the CerS6-mediated decrease in MCF-7 cell proliferation. ERK inhibition, but not Akt inhibition, along with mTOR inhibition synergistically reduced MCF-7 cell proliferation as measured by MTT assay. Notably, the expression of CerS6 and S1P receptor 2 (S1PR2), or CerS6 and sphingosine kinase 1 (SphK1), were negatively correlated according to the invasive breast carcinoma patient cohort in The Cancer Genome Atlas database. In addition, both SphK1 overexpression and S1P addition increased mTOR phosphorylation as shown by ELISA, while S1PR2 inhibition had the inverse effect. These data suggest that CerS6 and SphK1 regulate mTOR signaling in breast cancer cell proliferation. Moreover, mTOR activity can be regulated by the balance between S1P and C16-ceramide, which is generated by CerS6.

\section{Introduction}

Breast cancer is the most common malignancy diagnosed in women, and one in eight women is estimated to be diagnosed with breast cancer in her lifetime (1). Although advances in molecular biology have uncovered a large number of genomic aberrations in breast cancer, many of these aberrations converge on a few key pathways involved in cancer cell signal transduction, such as the phosphatidylinositol 3-kinase (PI3K)/Akt/mammalian target of rapamycin (mTOR) and the Raf/mitogen-activated protein kinase kinase (MEK)/extracellular signal-regulated kinase (ERK) pathways (2). Alterations in both signaling pathways are reported to play important roles in the carcinogenic process via modulation of cell proliferation, survival and invasion of breast cancer cells. Based on their critical role in breast cancer, inhibitors of these pathways have been developed for the treatment of breast cancer (2-5). The PI3K/Akt/mTOR pathway plays an important role in tumor cell proliferation, migration and survival; high PI3K or Akt activity has been considered indicative of poor prognosis 
in breast cancer $(4,6)$. In various human cancers, mTOR is also upregulated, and acts as a sensor for cell cycle progression from $\mathrm{G} 1$ to $\mathrm{S}$ phase, and it regulates translation of ribosomal proteins (7). Raf is a key serine-threonine protein kinase involved in the transduction of signals from the cytoplasm to the nucleus (3), and is part of the Ras/Raf/MEK/ERK protein kinase cascade, which plays a pivotal role in cell proliferation and cell fate determination (2).

Sphingolipids (SLs) are bioactive lipids that have crucial roles in the determination of cancer cell fate and modulate tumor suppression and survival. The concept of the SL rheostat describes that the balance of the interconvertible SL metabolites ceramide and sphingosine-1-phosphate (S1P), and their opposing signaling pathways, are major determinants of cell fate (8). Ceramide has been reported as a bioactive molecule that mediates cell death, whereas S1P induces tumor cell proliferation, resistance to chemotherapy and metastasis (9). Mammals have six ceramide synthases (CerS), with each CerS determining varying acyl chain lengths of ceramides $(10,11)$. For instance, CerS1 produces C18-ceramide, and CerS2 and CerS3 generate $\mathrm{C} 22-\mathrm{C} 24$ - and >C26-cermide, respectively. CerS4 synthesizes C20-ceramide, while both CerS5 and CerS6 can produce C16-ceramide. Recently, distinct roles of ceramide, depending on the acyl chain length, have been reported in cell death (12-14), mitochondrial function $(15,16)$, and fatty acid uptake (17).

$\mathrm{S} 1 \mathrm{P}$ is generated via phosphorylation of sphingosine by two sphingosine kinase (SphK) isoenzymes, SphK1 and SphK2. $\mathrm{S} 1 \mathrm{P}$ can be secreted, and then acts in an autocrine or paracrine manner (18). Secreted S1P can bind to five G protein-coupled $\mathrm{S} 1 \mathrm{P}$ receptors (S1PRs), which are expressed differentially in various cell types. Secreted S1P influences various cellular responses depending on the SIPR subtype. In addition to acting on receptors located on the plasma membrane, S1P also has intracellular effects, independently of S1PRs (19).

Recently, high levels of SLs, including S1P, and altered expression of CerS have been detected in human breast cancer samples $(20,21)$. CerS2 overexpression has been found to be correlated with breast cancer cell invasion and chemosensitivity $(22,23)$. In addition, several anticancer drugs such as doxorubicin, celecoxib and methotrexate increase C16-ceramide levels and reduce cell growth (24-26). However, the precise molecular mechanisms and downstream signaling pathways of ceramide depending on the acyl chain length and S1P have not yet been elucidated in breast cancer. In the present study, we uncovered an important role for the mTOR and ERK signaling pathways in SL-mediated reduction of breast cancer cell proliferation. The data further demonstrated that CerS6-induced C16-ceramide and the S1P/S1PR2 axis exhibit opposing effects on mTOR signaling.

\section{Materials and methods}

Materials. Wortmannin, SC79, MHY1485, fumonisin B1 (FB1), anti-HA (H6908), anti-flag (F3165), and anti- $\alpha$-tubulin (T9026) antibodies were purchased from Sigma-Aldrich/ Merck KGaA (Darmstadt, Germany). Antibodies for detecting phosphorylated (p)-Akt (9271), p-P70 S6 kinase (S6K) (9205), total-ERK (4695) and p-ERK (Thr202/Tyr204) (4370) were purchased from Cell Signaling Biotechnology, Inc. (Beverly,
MA, USA). The anti-CerS6 antibody (sc-100554) was obtained from Santa Cruz Biotechnology, Inc. (Santa Cruz, CA, USA). Anti-mouse horseradish peroxidase (HRP) (115-036-003) and anti-rabbit-HRP (111-035-003) antibodies were purchased from Jackson Laboratory (Bar Harbor, ME, USA). S1P and C16-ceramide were purchased from Avanti Polar Lipid (Alabaster, AL, USA). PD98059 and everolimus were obtained from Adooq BioScience (Irvine, CA, USA). Anti-SphK1 antibody was purchased from Abnova (Taipei, Taiwan).

Cell culture and transfection. MCF-7, BT-474 and MDA-MB361 cells, purchased from the American Type Culture Collection (ATCC; Rockville, MD, USA), were grown in Roswell Park Memorial Institute (RPMI)-1640 medium containing 10\% foetal bovine serum (FBS), and $2 \%$ penicillin/streptomycin (HyClone; GE Healthcare Life Sciences, Logan, UT, USA) in an atmosphere of $95 \%$ humidified air and $5 \% \mathrm{CO}_{2}$ at $37^{\circ} \mathrm{C}$. pcDNA3-HA vectors containing human CerS1, CerS2, CerS4, CerS5, CerS6 and pCMV-FLAG human SphK1 (kindly provided by A.H. Futerman, Weizmann Institute of Science, Rehovot, Israel) were transfected using Metafectene (Biotex Laboratories, Munich, Germany) according to the manufacturer's protocol. In some cases, 2-10 $\mu \mathrm{g}$ of pcDNA3-hCerS6-HA plasmid DNA in $10 \mu$ l final volume was used for different CerS6 expression.

Western blotting. MCF-7, BT-474 and MDA-MB-361 cells were lysed using radioimmunoprecipitation assay (RIPA) buffer [50 mM of Tris-Cl, pH 7.5, $150 \mathrm{mM}$ of $\mathrm{NaCl}, 1 \%$ Nonidet P-40, $0.5 \%$ sodium deoxycholate, $0.1 \%$ sodium dodecyl sulfate (SDS), and protease and phosphatase inhibitors (Sigma-Aldrich/Merck KGaA)]. Protein levels in cell lysate supernatants were calculated using Protein Assay Dye Reagent (Bio-Rad Laboratories, Hercules, CA, USA). Fifty micrograms of proteins were separated using denaturing $8 \%$ sodium dodecyl sulfate-polyacrylamide gel electrophoresis (SDS-PAGE) and transferred to nitrocellulose membranes (Bio-Rad Laboratories). The membranes were blocked in 5\% bovine serum albumin (BSA; Sigma-Aldrich/Merck KGaA) in Tris-buffered saline with $0.1 \%$ Tween-20 and subsequently incubated overnight at $4^{\circ} \mathrm{C}$ with the primary antibodies (1:1,000 dilution). After washing, HRP-conjugated secondary antibodies were attached for $1 \mathrm{~h}$ at room temperature. Protein bands were detected using the ChemiDoc MP imaging system (Bio-Rad Laboratories) and ECL Western Blotting Detection Reagents (Amersham Biosciences, Little Chalfont Bucks, UK).

mTOR (pSer2448) phosphorylation assay. MCF-7 cells were treated with C16-ceramide (10 pM to $100 \mathrm{nM})$ and $\mathrm{S} 1 \mathrm{P}(100 \mathrm{pM}$ to $1 \mu \mathrm{M})$ for $1 \mathrm{~h}$. For C16-ceramide treatment, MCF-7 cells were permeabilized with $10 \mu \mathrm{g} / \mathrm{ml}$ of digitonin for $10 \mathrm{~min}$. Cells were frozen immediately in liquid nitrogen and quantification of mTOR phosphorylation was performed using the mTOR (pSer2448) ELISA kit (Abcam, Cambridge, MA, USA) according to the manufacturer's protocol.

C16-ceramide treatment. C16-ceramide was added into the cell culture media to a final concentration of $1-5 \mu \mathrm{M}$ and cells were permeabilized with $10 \mu \mathrm{g} / \mathrm{ml}$ of digitonin for $10 \mathrm{~min}$ every $12 \mathrm{~h}$, as described previously (17). 
MTT assay. Cell growth was evaluated by MTT 3-[4,5-dimethylthiazol-2-yl]-2,5-diphenyl tetrazolium bromide assay as previously described (27). MCF-7 cells were seeded onto 96-well plates at a density of $5 \times 10^{4}$ cells/well. After transfection or treatment with various chemicals, cells were treated with MTT solution $(0.5 \mathrm{mg} / \mathrm{ml}$ final concentration), and further incubated for $4 \mathrm{~h}$. The supernatant was discarded and $200 \mu \mathrm{l}$ dimethyl sulfoxide (DMSO) was added to dissolve the purple formazan crystals. The production of solubilized purple formazan crystals was quantified by exposure to a wavelength of $540 \mathrm{~nm}$.

Bioinformatic data mining. The correlations between expression of different genes were analyzed with the invasive breast carcinoma patient cohort in The Cancer Genome Atlas (TCGA) database using cBioPortal (http://cbioportal.org) (28). The correlations between CerS6 and S1PR2, CerS6 and SPHK1, and S1PR2 and SPHK1 in the same patient cohort were further verified and analyzed using UCSC Xena (http://xena.ucsc.edu/).

Real-time polymerase chain reaction ( $q P C R)$. Total RNA from MCF-7 cells was extracted using RNeasy mini kits (Qiagen, Inc., Valencia, CA, USA), and cDNA was synthesized from the extracted RNA using a Verso cDNA Synthesis kit (Fisher Scientific, Hampton, NH, USA). qPCR was performed using the SYBR-Green Real-Time PCR Master Mix (Life Technologies, Grand Island, NY, USA) in an ABI PRISM 7500 Sequence Detection System (Applied Biosystems Inc.; Thermo Fisher Scientific, Inc., Waltham, MA, USA), as previously described (24). Relative gene expression was calculated using the $2^{-\Delta \Delta \mathrm{Cq}}$ method (24). The primers used in the present study are listed in Table I.

Liquid chromatography-electrospray ionization-tandem mass spectrometry (LC-ESI-MS-MS) analysis of ceramide. Ceramide analyses were conducted as previously described $(25,26)$. Briefly, lipids were extracted from $1 \times 10^{7}$ cells and introduced into a high-performance liquid chromatography (HPLC) system (Agilent 1,200 series; Agilent Technologies, Inc., Santa Clara, CA, USA) and separated through a reverse phase KINETEX C18 column $(2.1 \times 50 \mathrm{~mm}$, ID: $2.6 \mu \mathrm{m}$ ) (Phenomenex Inc., St. Louis, MO, USA). The HPLC column effluent was then injected into an API 3200 Triple quadrupole mass spectrometer (AB Sciex, Toronto, ON, Canada) and analyzed.

Statistical analysis. We performed three independent trials of all the experiments, and values are shown as means \pm standard error of the mean (SEM). Statistical significance was calculated using analysis of variance (ANOVA) followed by Tukey's post hoc test (GraphPad Prism 6.0; GraphPad Software, San Diego, CA, USA). $\mathrm{P}<0.05$ was considered indicative of statistical significance.

\section{Results}

C16-ceramide generated by CerS6 overexpression reduces phosphorylation of Akt, S6K and ERK. To elucidate the role of ceramide acyl chain length on breast cancer cell proliferation,
Table I. Primers used for real-time PCR.

\begin{tabular}{|c|c|}
\hline Gene & Primer sequences \\
\hline S1PR1 & $\begin{array}{l}\text { F: 5'-TCTCAGCAGTTCAGATCCGG-3' } \\
\text { R: 5'-CAAGGCTGGGTGGTTTCTTC-3' }\end{array}$ \\
\hline S1PR2 & $\begin{array}{l}\text { F: 5'-ATTCCTCCTGCCACCTTCTC-3' } \\
\text { R: 5'-GTGGATTTGGGCTCTGGATG-3' }\end{array}$ \\
\hline S1PR3 & $\begin{array}{l}\text { F: 5'-GCAGCTTCATCGTCTTGGAG-3' } \\
\text { R: 5'-GAGCCAGGTTGCCAATGAAA-3' }\end{array}$ \\
\hline S1PR4 & $\begin{array}{l}\text { F: 5'-CTGGGGATGCTGCCTTTG-3' } \\
\text { R: 5'-AGGCAGAAGAGGATGTAGCG-3' }\end{array}$ \\
\hline S1PR5 & $\begin{array}{l}\text { F: 5'-CCACGACTGTCTTCCCAAGT-3' } \\
\text { R: 5'-TTCCCCTGCATCTTTTCCGA-3' }\end{array}$ \\
\hline CerS1 & $\begin{array}{l}\text { F: 5'-CTTCTTCCATGACCCACCAT-3' } \\
\text { R: 5'-TAGAAGCTTCCCTGGAGCAG-3' }\end{array}$ \\
\hline CerS2 & $\begin{array}{l}\text { F: 5'-ATCGTCTTCGCCATTGTTTT-3' } \\
\text { R: 5'-GGCAGGATAGAGCTCCAGTG-3' }\end{array}$ \\
\hline CerS3 & $\begin{array}{l}\text { F: 5'-TCAGTAGCCAGCTTGTCCTC-3' } \\
\text { R: 5'-AGATGTGTCCCTCTGGTGAC-3' }\end{array}$ \\
\hline CerS4 & $\begin{array}{l}\text { F: 5'-GGAGGCCTGTAAGATGGTCA-3' } \\
\text { R: 5'-GAGGACCAGTCGGGTGTAGA-3' }\end{array}$ \\
\hline CerS5 & $\begin{array}{l}\text { F: 5'-TGTTCCTCTTTCACAGCTGGA-3' } \\
\text { R: 5'-GGATCTAGCTAGGGACCACG-3' }\end{array}$ \\
\hline CerS6 & $\begin{array}{l}\text { F: 5'-TGCCATTCTGGAAAAGGTCT-3' } \\
\text { R: 5'-ATGCTTCGAACATCCCAGTC-3' }\end{array}$ \\
\hline GAPDH & $\begin{array}{l}\text { F: 5'-ACACCCACTCCTCCACCTTT-3' } \\
\text { R: 5'-TGCTGTAGCCAAATTCGTTG-3' }\end{array}$ \\
\hline
\end{tabular}

relative expression of six CerS in the MCF-7 breast cancer cell line was first evaluated. The data showed that CerS2, CerS5 and CerS6 are the main CerS expressed in MCF-7 cells (Fig. 1A). Then, to explore the distinct role of ceramide in MCF-7 cell proliferation and intracellular signal propagation, CerS1, CerS2, CerS4, CerS5 and CerS6 were overexpressed in MCF-7 cells. All the CerS were successfully overexpressed in MCF-7 cells and a concomitant increase in the corresponding acyl chain length of ceramide was detected (Fig. 1B), as reported previously (10). CerS overexpression did not alter total ceramide or sphingosine levels (data not shown). Although overexpression of all the CerS reduced MCF-7 cell proliferation, CerS6 overexpression reduced $\mathrm{MCF}-7$ cell proliferation to a greater extent (Fig. 1C). Since the Akt/mTOR and ERK signaling pathways have been reported to be commonly dysregulated in breast cancer (2), phosphorylation of Akt, S6K (a downstream signaling molecule of mTOR) and ERK was examined using western blotting (Fig. 1D). Notably, overexpression of CerS6, but not of the other CerS enzymes, markedly reduced phosphorylation of Akt, S6K and ERK (Fig. 1D) and C16-ceramide treatment also showed similar inhibitory effects (Fig. 1E). To confirm whether these effects can be applicable to other breast cancer cells, we also examined BT-474 and MDA-MB-361 cells. Similar with MCF-7 cell data, CerS2, CerS5 and CerS6 were mainly expressed (Fig. 1F and G), and CerS6 
A

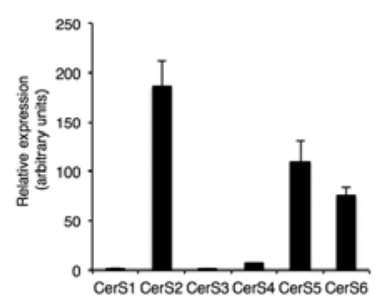

E

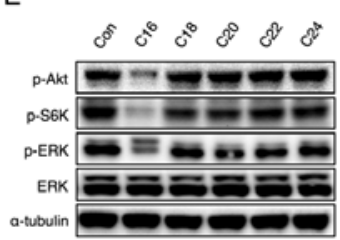

B

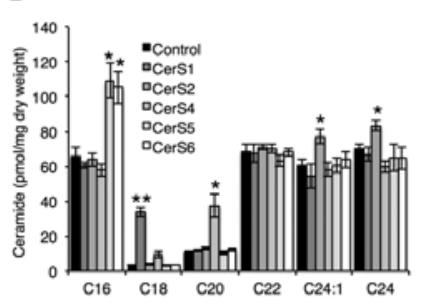

$\mathrm{F}$

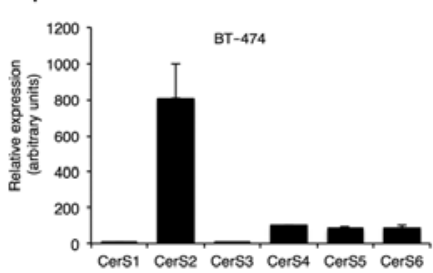

C

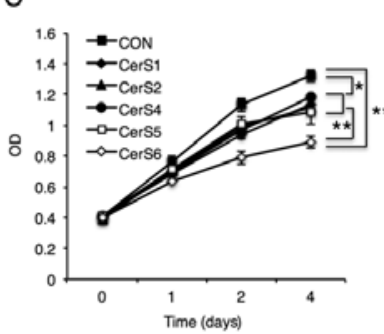

G

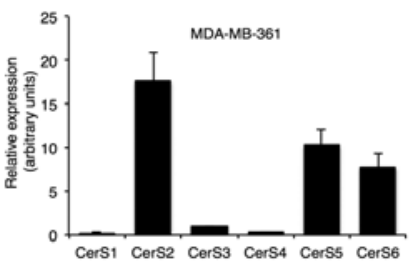

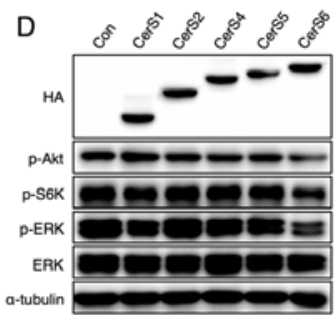

H

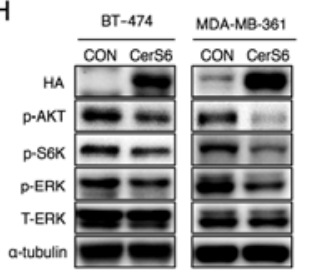

Figure 1. CerS6 overexpression reduces Akt, S6K and ERK phosphorylation. (A) Relative CerS mRNA levels in MCF-7 cells (n=3). (B) Acyl chain composition of ceramide in CerS-overexpressing MCF-7 cells $(\mathrm{n}=3)$. (C) Cell growth after CerS overexpression was determined using MTT assay. Western blot analyses of (D) Akt, S6K and ERK phosphorylation in MCF-7 cells after overexpression of different CerS and (E) treatment of ceramides with varying acyl chains (C16-C24). Relative CerS mRNA levels in (F) BT-474 and (G) MDA-MB-361 cells ( $\mathrm{n}=3$ ). (H) Western blot analyses of Akt, S6K and ERK phosphorylation in BT-474 and MDA-MB-361 cells after CerS6 overexpression. The data shown are representative of the means \pm SEM of three independent trials. "P<0.05, ${ }^{* * *} \mathrm{P}<0.01$.

overexpression diminished phosphorylation of Akt, S6K and ERK in the BT-474 and MDA-MB-361 cells (Fig. 1H).

To examine whether reduced phosphorylation of Akt, S6K and ERK by CerS6 overexpression is attributed to C16-ceramide generation, CerS6-overexpressing cells were treated with fumonisin B1, a CerS inhibitor (29). Fumonisin B1 (FB1) treatment reversed the phosphorylation of Akt, S6K and ERK (Fig. 2A), and C16-ceramide treatment also caused a similar reduction in Akt, S6K and ERK with CerS6 overexpression dose-dependently (Fig. 2B). In addition, CerS6 overexpression reduced phosphorylation of Akt, S6K, and ERK in a dose-dependent manner (Fig. 2C). Finally, C16-ceramide treatment dose-dependently reduced MCF-7 cell proliferation (Fig. 2D). These results indicate that CerS6-induced elevation of C16-ceramide reduces the phosphorylation of Akt, mTOR and ERK, and attenuates breast cancer cell proliferation.

Phosphorylation of mTOR, but not Akt, plays an essential role in CerS6-induced reduction of breast cancer cell proliferation. CerS6 overexpression affected several pathways. To identify the specific pathways invoked by CerS6 overexpression, we used specific inhibitors of the Akt, S6K, and ERK signaling pathways. Treatment of MCF-7 cells with wortmannin (an Akt inhibitor), everolimus (an mTOR inhibitor), and PD98059 (an ERK inhibitor) successfully inhibited phosphorylation of the target molecules (Fig. 3A). Although Akt inhibition diminished MCF-7 cell proliferation, the effect was minimal (Fig. 3B). In contrast, mTOR inhibition significantly reduced MCF-7 cell proliferation (Fig. 3C), and ERK inhibition significantly diminished MCF-7 cell proliferation only at the high dosage $(10 \mu \mathrm{M})$ (Fig. 3D). These results suggest an important role for mTOR and ERK in CerS6-mediated regulation of MCF-7 cell proliferation.

Next, specific activators of Akt (SC79) and mTOR (MHY1485) were utilized to elucidate the distinct signals involved in CerS6-mediated reduction of MCF-7 cell proliferation. ERK activation studies could not be conducted due to the absence of specific ERK activators. As expected, treatment of MCF-7 cells with MHY1485 and SC79 elevated the phosphorylation levels of S6K and Akt, respectively (Fig. 4A). In accordance with the minimal effect of Akt inhibition in MCF-7 cell proliferation (Fig. 3B), Akt activation using SC79 did not affect CerS6-mediated reduction of MCF-7 cell proliferation (Fig. 4B). Unlike Akt activation, mTOR activation reversed the CerS6-mediated attenuation of MCF-7 cell proliferation (Fig. 4C), suggesting a critical role for the mTOR signaling pathway in CerS6-mediated reduction of breast cancer cell proliferation.

mTOR and ERK signaling exhibit synergism in breast cancer cell proliferation. Finally, the synergistic effects of Akt and ERK signals with the mTOR pathway on breast cancer cell proliferation were examined. Although concomitant Akt and mTOR inhibition using wortmannin and everolimus did not impose additional effects on MCF-7 cell proliferation, compared with treatment with inhibition of either alone (Fig. 5A), co-inhibition of ERK and mTOR using PD98059 and everolimus synergistically reduced MCF-7 cell growth (Fig. 5B). Co-inhibition of Akt and ERK using wortmannin and PD98059 did not exhibit synergistic effects on MCF-7 cell proliferation (Fig. 5C). These data suggest that CerS6-mediated reduction of breast cancer cell proliferation may be achieved by synergistic effects of mTOR and ERK signaling pathways.

CerS6 and SphK1/S1PR2 expression exhibit a negative correlation in human breast cancer cohort data. SL metabolism is tightly regulated, and ceramide can also be converted to various SLs, including S1P. In addition, an important role of $\mathrm{S} 1 \mathrm{P}$ in various cancers has been relatively well established, and the SL rheostat model suggests that the balance between 
A

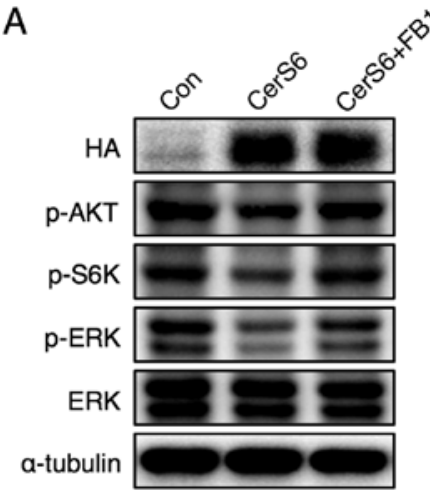

C

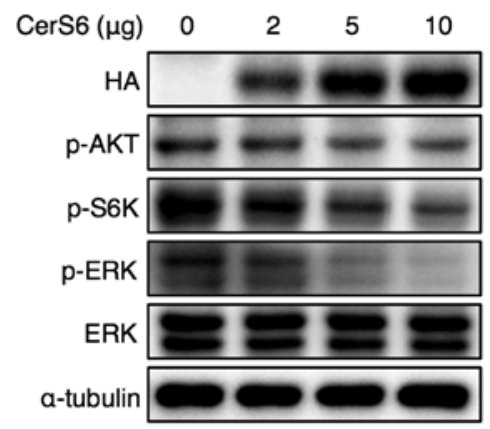

B

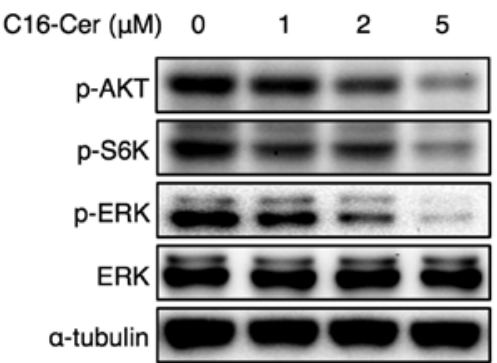

D

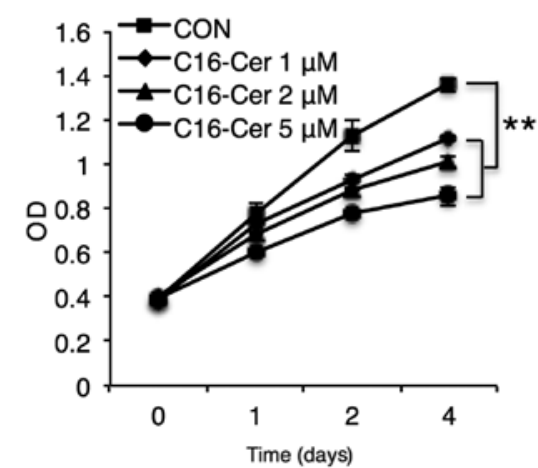

Figure 2. CerS6 overexpression or C16-ceramide treatment decreases MCF-7 cell proliferation. Representative western blot analysis of Akt, S6K, and ERK phosphorylation (A) in CerS6-overexpressing MCF-7 cells, with or without fumonisin B1 (FB1) $(10 \mu \mathrm{M})$ treatment, (B) in cells treated with C16-ceramide (1 to $5 \mu \mathrm{M}$ ), and (C) in cells transfected with plasmids expressing CerS6 (2 to $10 \mu \mathrm{g}$ ). (D) Cell growth was assessed after C16-ceramide (1 to $5 \mu \mathrm{M})$ treatment for the indicated times. The data shown are representative of the means \pm SEM of three independent trials. ${ }^{* *} \mathrm{P}<0.01$.

A

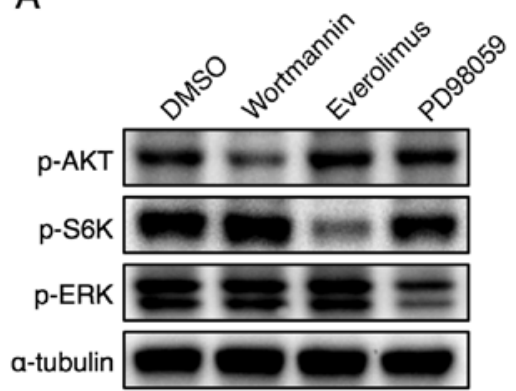

C

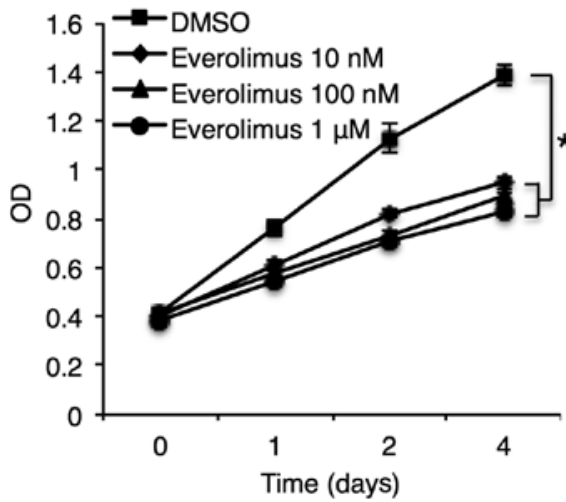

B
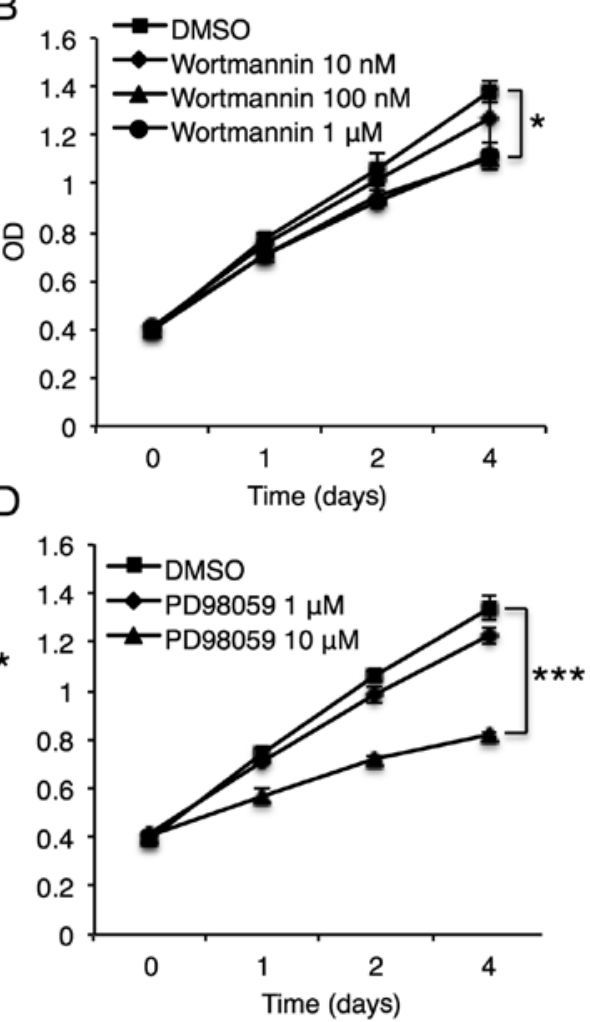

Figure 3. Inhibition of MCF-7 cell growth is the most effective in mTOR-inhibited cells, compared with that in Akt- or ERK-inhibited cells. (A) Representative western blot analysis of Akt, S6K and ERK phosphorylation in MCF-7 cells upon treatment with specific inhibitors: Wortmannin (an Akt inhibitor), everolimus (an mTOR inhibitor) and PD98059 (an ERK inhibitor). MCF-7 cell proliferation was also evaluated after treatment with (B) wortmannin, (C) everolimus, or (D) PD98059. The data shown are representative of the means \pm SEM of three independent trials. ${ }^{*} \mathrm{P}<0.05,{ }^{* * *} \mathrm{P}<0.001$. 

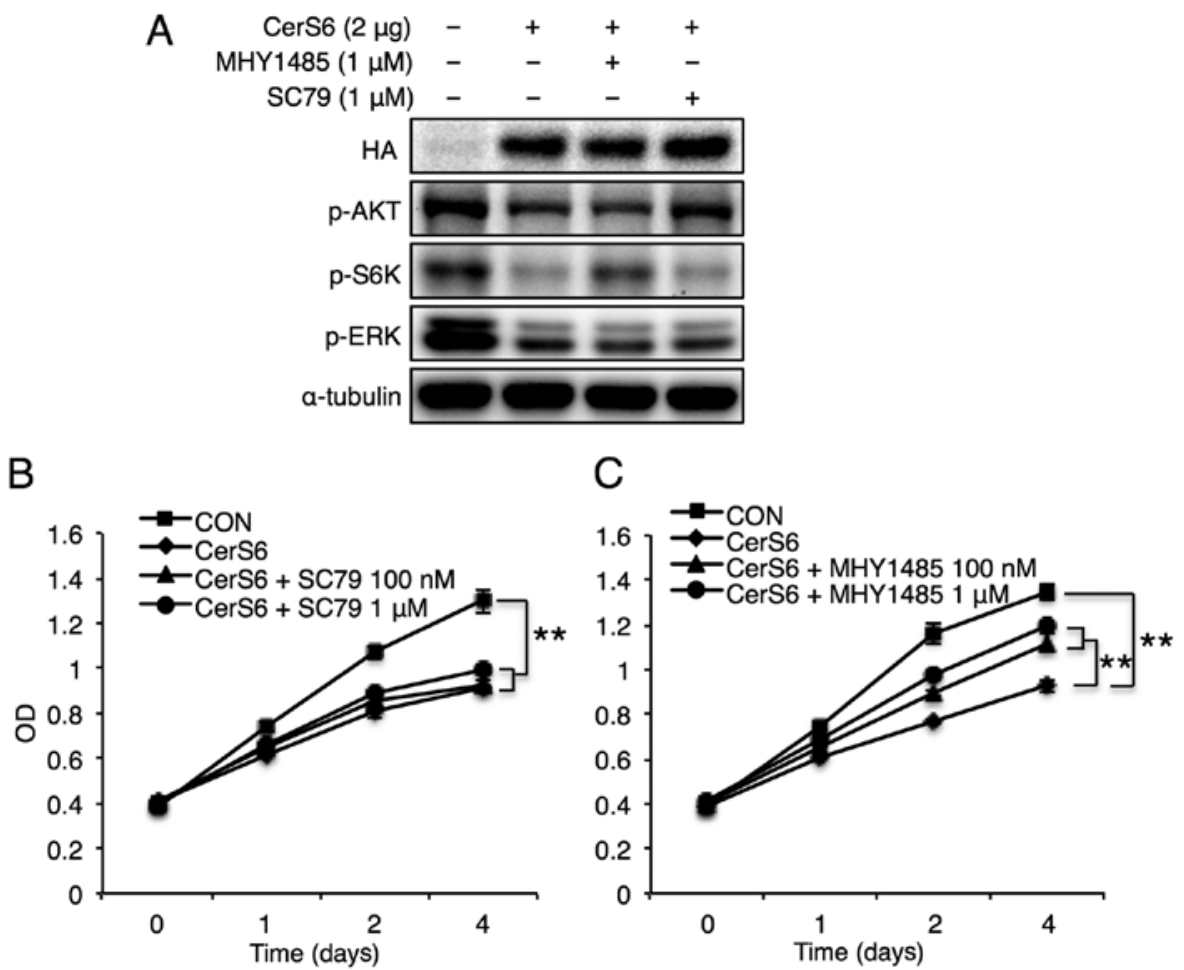

Figure 4. mTOR activation reverses CerS6-mediated reduction of MCF-7 cell growth. (A) Representative western blot analysis of Akt, S6K and ERK phosphorylation in CerS6-overexpressing MCF-7 cells treated with SC79 (an Akt activator, $1 \mu \mathrm{M}$ ) or MHY1485 (an mTOR activator, $1 \mu \mathrm{M}$ ). The proliferation of CerS6-overexpressing MCF-7 cells was assessed after (B) SC79 or (C) MHY1485 treatment. The data shown are representative of the means \pm SEM of three independent trials. ${ }^{* *} \mathrm{P}<0.01$.
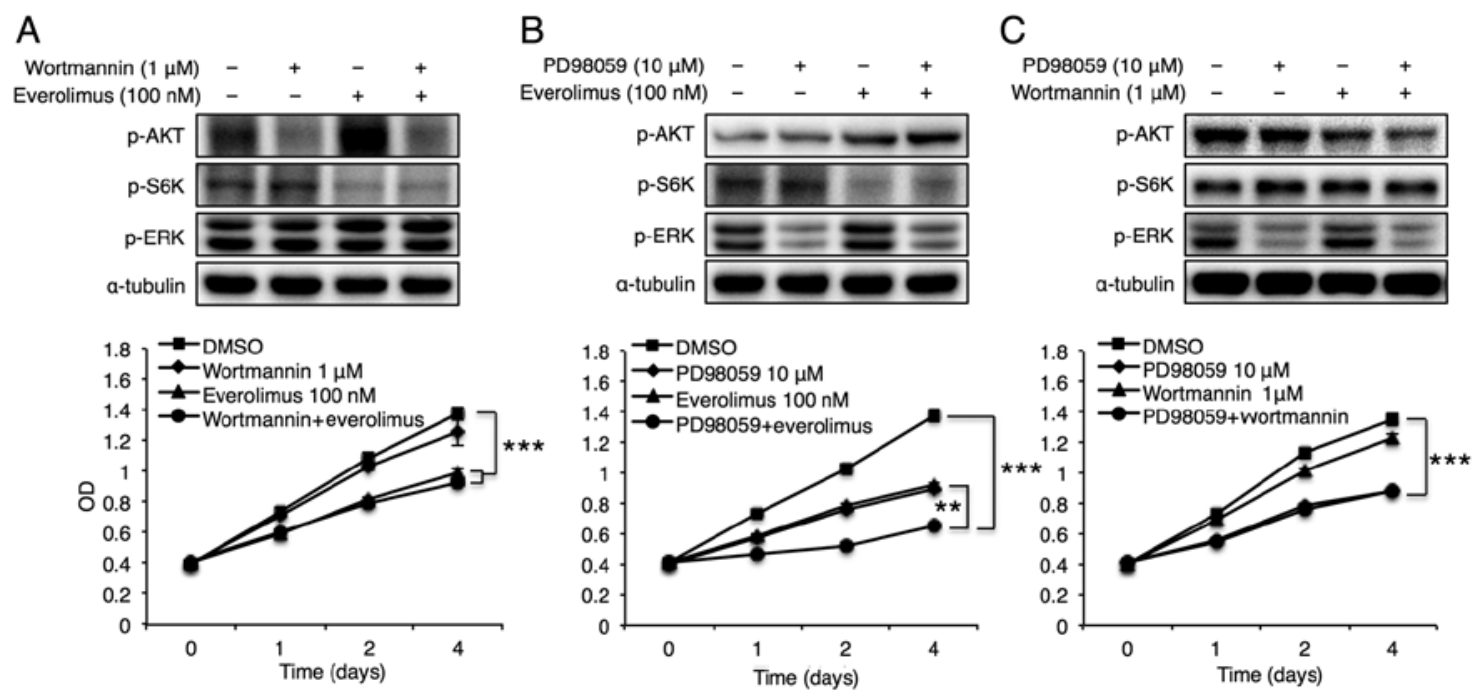

Figure 5. Co-inhibition of mTOR and ERK reduces MCF-7 cell growth in a synergistic manner. Representative western blot analysis of Akt, S6K, and ERK phosphorylation (upper panels) and cell growth (lower panels) (A) in MCF-7 cells after co-treatment with wortmannin (1 $\mu \mathrm{M})$ and everolimus (100 nM), (B) in MCF-7 cells after co-treatment with PD98059 $(10 \mu \mathrm{M})$ and everolimus $(100 \mathrm{nM})$, and (C) in MCF-7 cells after co-treatment with PD98059 (10 $\mu \mathrm{M})$ and wortmannin $(1 \mu \mathrm{M})$. The data shown are representative of the means \pm SEM of three independent trials. ${ }^{* *} \mathrm{P}<0.01,{ }^{* * * *} \mathrm{P}<0.001$.

ceramide and $\mathrm{S} 1 \mathrm{P}$ is an important determinant of cell fate (8). We conducted data mining in an invasive breast carcinoma cohort of the TCGA database (30) using cBioPortal to explore the correlation between SL-metabolizing genes with CerS6 in breast cancer. Regression analysis indicated that CERS6 and S1PR2 expression had a negative correlation (Pearson's correlation coefficient $=-0.38$; Spearman's correlation coefficient=-0.5; Fig. 6A). The expression of CERS6 and SPHKI also had a negative correlation (Pearson's correlation coefficient=-0.35; Spearman's correlation coefficient $=-0.52$; Fig. 6B). Importantly, S1PR2 and SPHK1 expression was positively correlated (Pearson's correlation coefficient $=0.30$; Spearman's correlation coefficient $=0.51$; Fig. 6C). We also generated the heatmap of SIPR2 and SPHK1 and analyzed co-expression of SIPR2 and SPHK1 in the same data using another tool, the Xena browser. Results revealed that among 
A

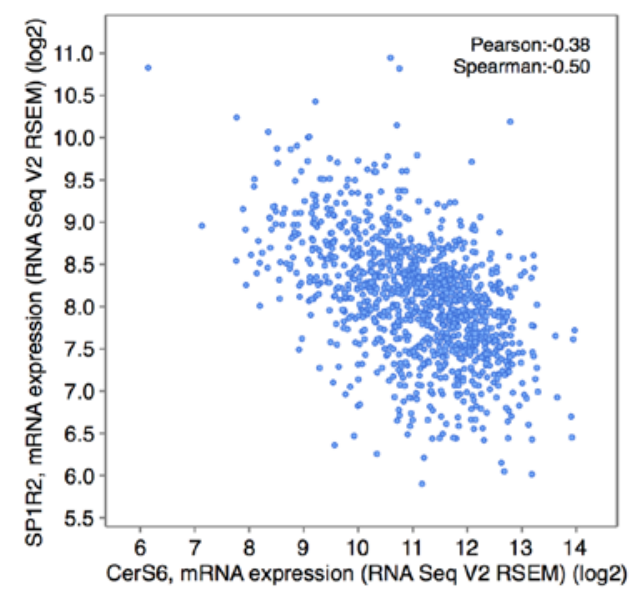

C

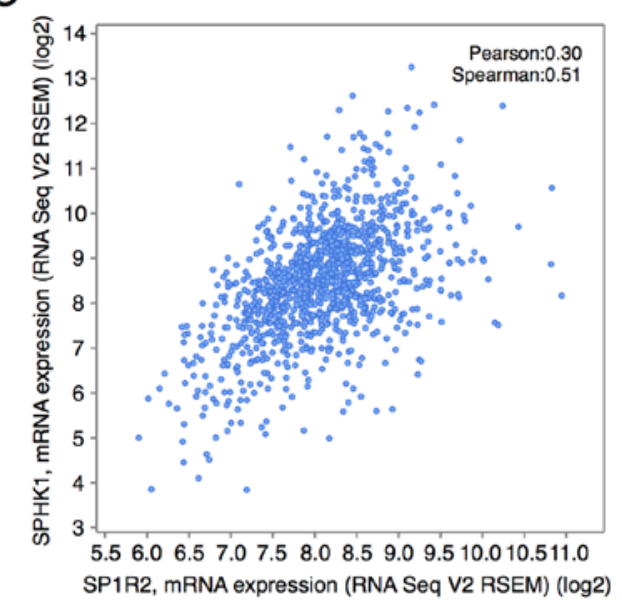

B

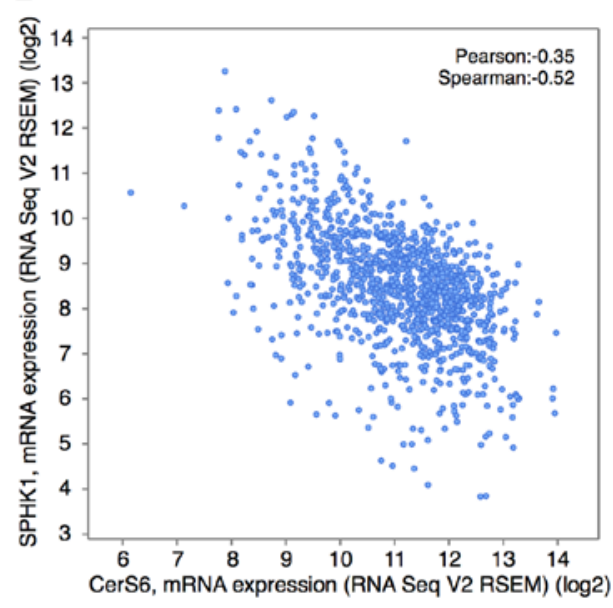

D

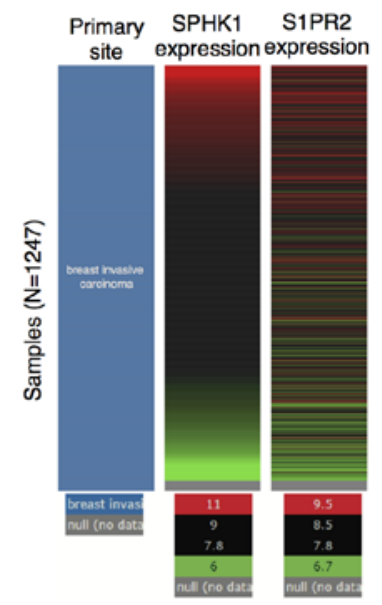

Pearson's rho $r=0.4970$ Spearman's rank rho $\mathrm{p}=0.4692$

$E$

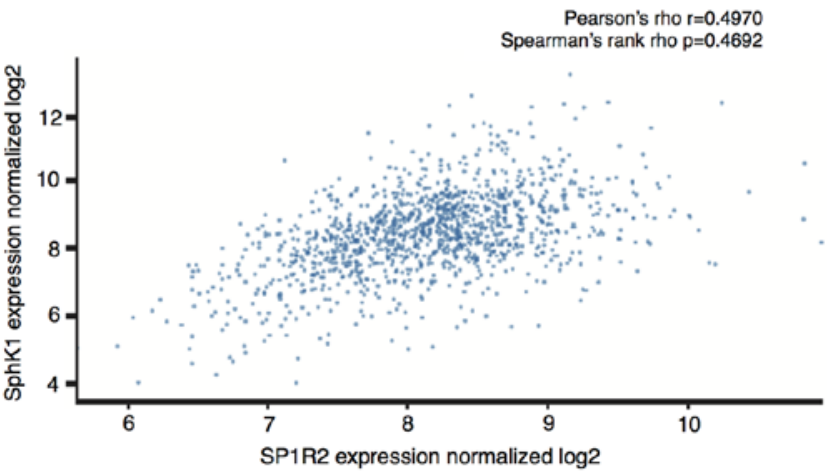

Figure 6. Correlation of CerS6, SphK1, and S1PR2 expression in invasive breast carcinoma. Simple correlation analysis was presented using cBioPortal (A) between CerS6 and SphK1 expression, (B) between CerS6 and S1PR2 expression, and (C) between SphK1 and S1PR2 expression in invasive breast carcinoma. (D) The heatmap analysis and (E) Simple correlation analysis between SphK1 and S1PR2 are represented using UCSC Xena in the invasive breast carcinoma cohort of the TCGA database analysis.

1,247 invasive breast carcinoma patients, in whom gene expression was examined using RNAseq, the expression of SIPR2 and SPHK1 was highly correlated (Pearson's correlation coefficient $=0.4970$; Spearman's correlation coefficient $=0.4692$; Fig. 6D and E). There was no significant correlation between the expression of CerS6 and SPHK2, or between expression of CerS6 and other S1PR subtypes (data not shown).

C16-ceramide and SIP have opposite effects on mTOR, but not ERK, phosphorylation. Since CerS6 and SphK1/S1PR2 expression showed negative correlations in the human breast cancer cohort data, we examined whether the SphK1/S1PR2 axis can exert opposing effects on intracellular signaling with CerS6 in breast cancer cells. MCF-7 cells were treated with different doses of C16-ceramide or S1P, the product of SphK1, and the effect on mTOR signaling was assessed by monitoring mTOR phosphorylation. C16-ceramide treatment dose-dependently reduced phosphorylation of mTOR (Fig. 7A), while S1P activated mTOR signaling in MCF-7 cells in a dose-dependent manner (Fig. 7B). As S1P can be secreted and bind to five $G$ 
A

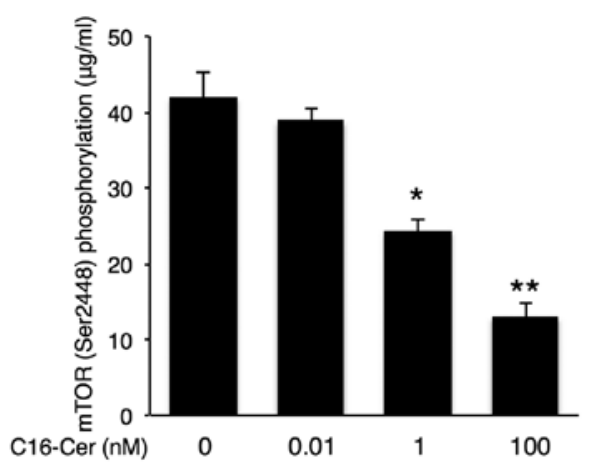

B

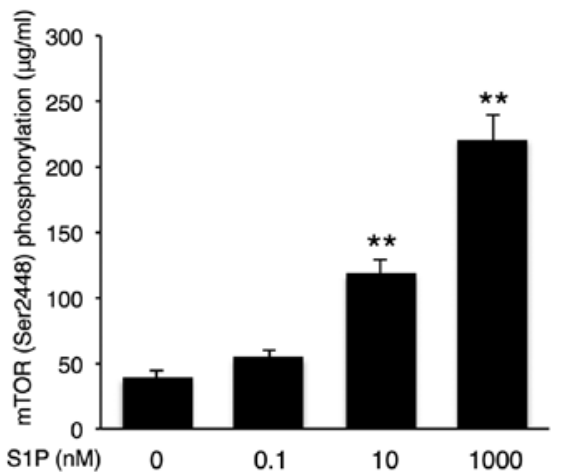

C

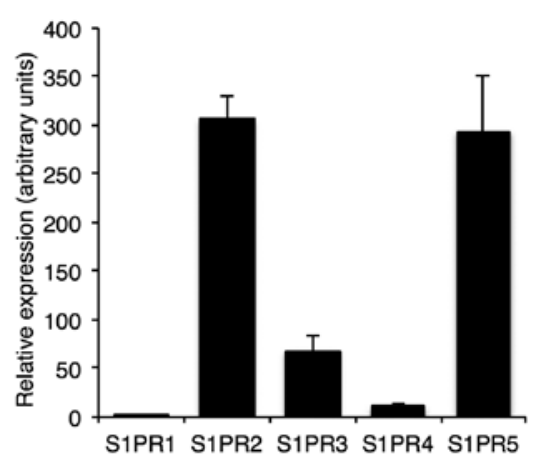

D

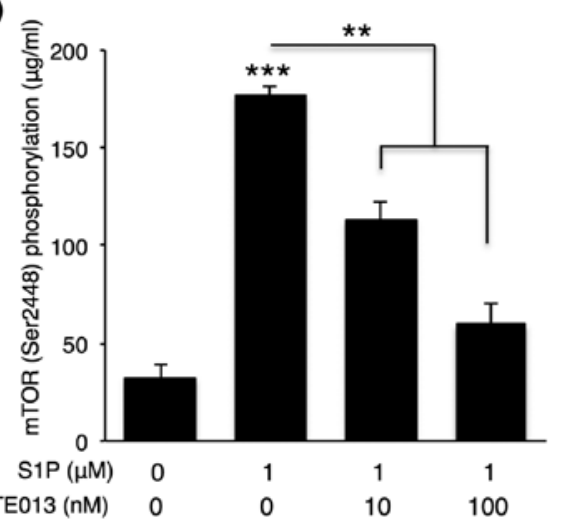

Figure 7. S1P activates mTOR signaling via S1PR2 in MCF-7 cells. Quantification of mTOR phosphorylation in MCF-7 cells was performed using the mTOR (pSer2448) ELISA kit (Abcam, Cambridge, MA, USA). (A) Quantification of mTOR phosphorylation in MCF-7 cells treated with various concentrations of C16-ceramide (10 pM to $100 \mathrm{nM}$ ) for $1 \mathrm{~h}$. (B) Quantification of mTOR phosphorylation in MCF-7 cells treated with various concentrations of S1P (100 pM to $1 \mu \mathrm{M}$ ) for $1 \mathrm{~h}$. (C) Relative S1PR mRNA levels in MCF-7 cells (n=3). (D) Quantification of mTOR phosphorylation in S1P (1 $\mu \mathrm{M})$-incubated MCF-7 cells pre-treated with JTE013 (an S1PR2 inhibitor, 10 to $100 \mathrm{nM}$ ). The data shown are representative of the means \pm SEM of three independent trials. ${ }^{*} \mathrm{P}<0.05$, ${ }^{* *} \mathrm{P}<0.01,{ }^{* * * *} \mathrm{P}<0.001$

A

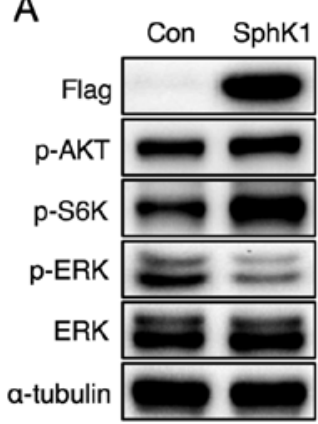

B

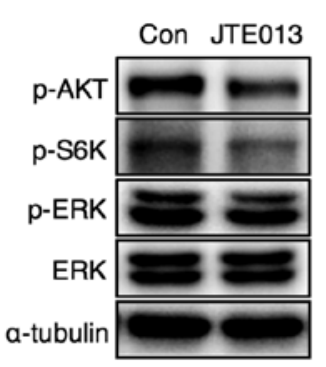

$\mathrm{C}$

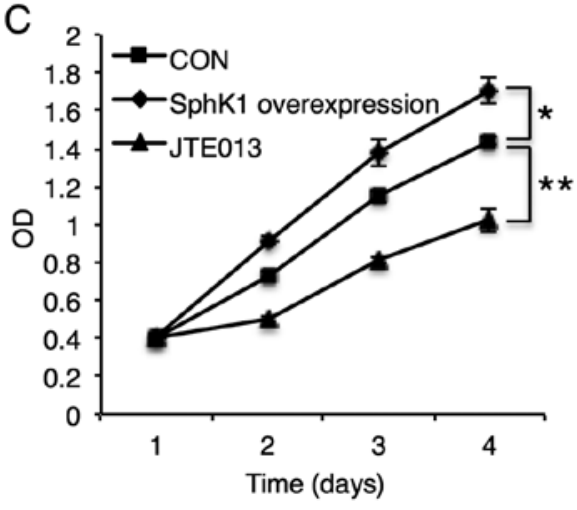

Figure 8. The SphK1/S1PR2 pathway plays an important role in MCF-7 cell proliferation. Western blot analyses of Akt, S6K, and ERK phosphorylation in MCF-7 cells after (A) SphK1 overexpression or (B) JTE013 (1 $\mu \mathrm{M})$ treatment. (C) Cell growth was evaluated after SphK1 overexpression or JTE013 treatment. The data shown are representative of the means \pm SEM of three independent trials. ${ }^{*} \mathrm{P}<0.05,{ }^{* *} \mathrm{P}<0.01$.

protein-coupled S1PRs (18), we evaluated the expression of S1PR subtypes in MCF-7 cells using qPCR. S1PR2 and S1PR5 were the main S1PRs expressed in MCF-7 cells (Fig. 7C), and S1PR2 inhibition using JTE013 abolished S1P-induced mTOR phosphorylation (Fig. 7D). These data suggest that S1P generated by SphK1 can activate mTOR signaling via S1PR2. Due to the absence of a specific S1PR5 inhibitor, S1PR5 inhibition analyses could not be conducted.
In accordance with the S1P-induced mTOR phosphorylation data (Fig. 7B), SphK1 overexpression increased phosphorylation of S6K and MCF-7 cell proliferation (Fig. 8A and C), effects that were opposite of those induced by CerS6 overexpression (Fig. 2C and D). SphK1 overexpression also increased Akt phosphorylation, but reduced ERK phosphorylation (Fig. 8A). Finally, S1PR2 inhibition diminished S6K phosphorylation and MCF-7 cell proliferation (Fig. 8B and C), confirming the 
involvement of S1PR2 in regulating MCF-7 cell proliferation. Although S1PR2 inhibition reduced Akt phosphorylation, it did not affect ERK phosphorylation. Sphingosine has been reported as a pro-apoptotic lipid (31), and we examined whether sphingosine can exert similar effects with S1P. Unlike S1P, sphingosine treatment diminished AKT and mTOR phosphorylation, and decreased MCF-7 cell proliferation (data not shown). Therefore, these results indicate that the balance between CerS6/C16-ceramide and the SphK1/S1P/S1PR2 axis can determine the fate of mTOR activation and MCF-7 cell proliferation.

\section{Discussion}

SLs have been implicated in many of the most important and fundamental aspects of cellular biology, including growth, differentiation, apoptosis and oncogenesis (32). SLs are not only essential constituents of cellular membranes, but also crucial mediators in the regulation of signaling pathways. Although several reports have suggested the involvement of SLs in breast cancer pathogenesis (20-23), the underlying signaling pathways have not yet been elucidated. In the present study, we demonstrated that the mTOR signaling pathway is crucial in the SL-mediated regulation of breast cancer cell proliferation, including those mediated by $\mathrm{C} 16$-ceramide and S1P. Additionally, S1P exerts its effects on breast cancer cell proliferation through S1PR2. Therefore, C16-ceramide and S1PR2 modulators may prove to be potential novel strategies for the treatment of breast cancer.

We found that CerS6 overexpression led to the elevation of $\mathrm{C} 16$ ceramide levels, and decreased both Akt/mTOR and ERK phosphorylation, which plays a critical role in the proliferation of breast cancer $(2,33,34)$. In accordance with previous reports (24-26), which showed that several anticancer reagents such as doxorubicin, celecoxib and methotrexate increase C16-ceramide, increased C16-ceramide induced by CerS6 overexpression reduced breast cancer cell growth with concomitant inhibition of both the Akt/mTOR and ERK pathways. Because the Akt/mTOR pathway is highly dysregulated in breast cancer and it also mediates resistance to endocrine therapies, mTOR inhibition has received significant attention as a novel therapy against breast cancer (35). In addition, combination treatment with $\mathrm{mTOR}$ inhibitors along with steroidal aromatase inhibitors improved progression-free survival in hormone receptor-positive advanced breast cancer patients, compared with steroidal aromatase inhibition monotherapy (36). However, combined treatment did not confer a statistically significant improvement in overall survival (37), and initial studies with rapalogs, allosteric inhibitors of mTORC1, have shown limited clinical efficacy due to the release of a negative regulatory feedback loop that triggers Akt and ERK signaling (35). In other words, inhibition of one pathway can still result in the maintenance or activation of signaling via other reciprocal pathways, as $\mathrm{PI} 3 \mathrm{~K} / \mathrm{Akt} / \mathrm{mTOR}$ and Raf/ERK cascades are interconnected at multiple points of convergence, via cross-talk, and feedback loops (2). In the present study, we found that CerS6 overexpression diminished all the essential signaling cascades, including Akt, mTOR and ERK. Therefore, CerS6 overexpression and C16-ceramide elevation may overcome the limitation of current signaling inhibitors.
In the present study, CerS6 expression was negatively correlated with both SphK1 and S1PR2 expression in a human TCGA data, but not with SphK2 or S1PR1, 3, 4, and 5 (data not shown). However, overexpression of either CerS6 or SphK1 did not affect the expression levels of the others (data not shown), suggesting an indirect correlation between CerS6 and SphK1 expression. In contrast to the inhibitory effect of CerS6 overexpression on the mTOR signaling pathway, SphK1 overexpression activated mTOR downstream cascades. Additionally, S1PR2 inhibition reduced Akt/mTOR phosphorylation, implying that S1P generated by SphK1 could bind to S1PR2 and then activate Akt/mTOR signaling. Because S1PR2, and S1PR5 are the two main S1PR subtypes expressed in MCF-7 cells, S1PR2 is likely to play an important role in S1P binding. Although a negative correlation between CerS2, CerS4 and SphK1 was reported in a previous study (21), CerS2, CerS4 or SphK1 overexpression did not affect the expression of each other in our analyses (data not shown), suggesting an indirect mechanism of regulation of these 3 proteins. A previous study reported the opposing effects of CerS1 and SphK1 in sensitivity against cancer reagents (38). Similarly, in the present study, opposing effects of CerS6 and SphK1/S1PR2 on the mTOR signaling pathway were demonstrated in breast cancer cells. In 1996, the term 'SL rheostat' was first proposed to tie together several seminal findings demonstrating the capacity of S1P and ceramide to differentially regulate cell growth and survival by modulation of opposing signaling pathways (8). The present study supports this model, showing that the balance between CerS6, which generates C16-ceramide, and SphK1, which generates S1P, might play an important role in determining breast cancer cell growth and destiny. In contrast to the data that CerS6 and SphK1/S1PR2 exert contrasting effects on mTOR signaling, they both reduced ERK phosphorylation in breast cancer cells. Ceramide can be metabolized by ceramidase to sphingosine, and sphingosine can be phosphorylated by one of two SphKs (39). Whether reduced ERK phosphorylation by CerS6 overexpression can be attributed to subsequent conversion of ceramide to S1P or not remains to be elucidated.

Although CerS2, CerS4 and CerS6 expression have been reported to be elevated in breast cancer $(21,40)$, the role of CerS in breast cancer is not yet understood. This study demonstrated that overexpression of CerS6, but not of other CerS, reduced mTOR phosphorylation. Furthermore, the reduction of breast cancer cell proliferation by CerS6 was the most effective, compared with other CerS, suggesting that variations in acyl chain length yield disparate effects of ceramides on cellular functions. Thus, increased CerS6 expression in breast cancer may reflect a compensatory increase to induce cancer cell death. However, ceramide can be metabolized by sphingomyelinase to sphingomyelin, and by glucosylceramide synthase to glucosylceramide, which can be further metabolized to various glycosphingolipids. In addition, ceramide glycosylation has been reported to play an important role in maintenance of the properties of breast cancer stemness (41). Therefore, the balance among final SL products in breast cancer may determine the final destiny of cells.

Both CerS5 and CerS6 have been reported to generate C16-ceramide (10). However, only CerS6, but not CerS5 overexpression reduced Akt, ERK and mTOR signaling. The different role of CerS5 and CerS6 has been reported 
previously (17,42). Differential regulation of CerS5 and CerS6 in gene expression such as fatty acid transport protein 5 and fatty acid binding protein 1 has been reported previously (17). Knockdown of CerS6 with siRNA reduced glutamate-triggered oligodendrocyte apoptosis, whereas knockdown of CerS5 had no effect (42). Since only CerS6, but not CerS5, was detected in mitochondria (43), difference in the final intracellular localization of C16-ceramide may exist between CerS5 and CerS6. However, the precise mechanism involved in the difference of CerS5 and CerS6 still remains to be elucidated.

In summary, this study demonstrated the involvement of mTOR and ERK signaling cascades in the reduction of breast cancer cell proliferation by CerS6. Our data also demonstrated that the balance between $\mathrm{C} 16$-ceramide and S1P/S1PR2 plays a critical role in the regulation of mTOR activation. Considering the inhibitory effects of CerS6 on Akt, mTOR and ERK, which are critical breast cancer cell survival and proliferation regulatory pathways, C16-ceramide and CerS6 overexpression may overcome the limitation of current anti-breast cancer agents. Therefore, CerS6 and S1PR2 may represent novel therapeutic targets for breast cancer, especially for use as combinatory therapies with current anticancer agents.

\section{Acknowledgements}

Not applicable.

\section{Funding}

This work was supported by funding from the Gachon University Gil Medical Center (grant no. 2014-20) and the Basic Science Research Program through the National Research Foundation of Korea (NRF) funded by the Ministry of Education, Science and Technology (NRF-2015R1C1A1A0 1054452).

\section{Availability of data and materials}

The datasets used during the present study are available from the corresponding author upon reasonable request.

\section{Authors' contributions}

MHK, JWP, EJL, SK, IP and WJP contributed to the conception and design of the study. MHK, JWP, EJL, SK, SHS, JHA, JJ, IK and WJP performed the experiments. SHS, JHA, JJ and WJP contributed to the acquisition of data. MHK, JWP, SHS, IP and WJP wrote the manuscript. JWP, IP and WJP reviewed and edited the manuscript. All authors read and approved the manuscript, and agree to be accountable for all aspects of the research in ensuring that the accuracy or integrity of any part of the work are appropriately investigated and resolved.

\section{Ethics approval and consent to participate}

Written informed consent was obtained from each study participant.

\section{Patient consent for publication}

Not applicable.

\section{Competing interests}

The authors declare that they have no competing interest.

\section{References}

1. Li D, Bi FF, Chen NN, Cao JM, Sun WP, Zhou YM, Li CY and Yang Q: A novel crosstalk between BRCA1 and poly (ADP-ribose) polymerase 1 in breast cancer. Cell Cycle 13: 3442-3449, 2014.

2. Saini KS, Loi S, de Azambuja E, Metzger-Filho O, Saini ML, Ignatiadis M, Dancey JE and Piccart-Gebhart MJ: Targeting the PI3K/AKT/mTOR and Raf/MEK/ERK pathways in the treatment of breast cancer. Cancer Treat Rev 39: 935-946, 2013.

3. Weinstein-Oppenheimer CR, Burrows C, Steelman LS and McCubrey JA: The effects of beta-estradiol on Raf activity, cell cycle progression and growth factor synthesis in the MCF-7 breast cancer cell line. Cancer Biol Ther 1: 256-262, 2002.

4. Hurvitz SA, Kalous O, Conklin D, Desai AJ, Dering J, Anderson L, O'Brien NA, Kolarova T, Finn RS, Linnartz R, et al: In vitro activity of the mTOR inhibitor everolimus, in a large panel of breast cancer cell lines and analysis for predictors of response. Breast Cancer Res Treat 149: 669-680, 2015.

5. Liu $\mathrm{H}, \mathrm{Hu} \mathrm{C}, \mathrm{Wu} \mathrm{X}$ and $\mathrm{Li} \mathrm{Z}$ : Equol elicits estrogenic activities via PI3K/akt pathway in the estrogen receptor-positive MCF-7 cells. Mol Cell Toxicol 10: 285-291, 2014.

6. Paplomata E and O'Regan R: The PI3K/AKT/mTOR pathway in breast cancer: Targets, trials and biomarkers. Ther Adv Med Oncol 6: 154-166, 2014.

7. Bjornsti MA and Houghton PJ: The TOR pathway: A target for cancer therapy. Nat Rev Cancer 4: 335-348, 2004.

8. Newton J, Lima S, Maceyka M and Spiegel S: Revisiting the sphingolipid rheostat: Evolving concepts in cancer therapy. Exp Cell Res 333: 195-200, 2015.

9. Ogretmen B: Sphingolipid metabolism in cancer signalling and therapy. Nat Rev Cancer 18: 33-50, 2018.

10. Park WJ and Park JW: The effect of altered sphingolipid acyl chain length on various disease models. Biol Chem 396: 693-705, 2015.

11. Park JW, Park WJ and Futerman AH: Ceramide synthases as potential targets for therapeutic intervention in human diseases. Biochim Biophys Acta 1841: 671-681, 2014.

12. Karahatay S, Thomas K, Koybasi S, Senkal CE, Elojeimy S, Liu X, Bielawski J, Day TA, Gillespie MB, Sinha D, et al: Clinical relevance of ceramide metabolism in the pathogenesis of human head and neck squamous cell carcinoma (HNSCC): Attenuation of $\mathrm{C}_{18}$-ceramide in HNSCC tumors correlates with lymphovascular invasion and nodal metastasis. Cancer Lett 256: 101-111, 2007.

13. Mesicek J,Lee H,Feldman T, Jiang X, Skobeleva A,Berdyshev EV, Haimovitz-Friedman A, Fuks Z and Kolesnick R: Ceramide synthases 2,5 , and 6 confer distinct roles in radiation-induced apoptosis in HeLa cells. Cell Signal 22: 1300-1307, 2010.

14. Hartmann D, Lucks J, Fuchs S, Schiffmann S, Schreiber Y, Ferreirós N, Merkens J, Marschalek R, Geisslinger G and Grösch S: Long chain ceramides and very long chain ceramides have opposite effects on human breast and colon cancer cell growth. Int J Biochem Cell Biol 44: 620-628, 2012.

15. Zigdon H, Kogot-Levin A, Park JW, Goldschmidt R, Kelly S, Merrill AH Jr, Scherz A, Pewzner-Jung Y, Saada A and Futerman AH: Ablation of ceramide synthase 2 causes chronic oxidative stress due to disruption of the mitochondrial respiratory chain. J Biol Chem 288: 4947-4956, 2013.

16. Raichur S, Wang ST, Chan PW, Li Y, Ching J, Chaurasia B, Dogra S, Öhman MK, Takeda K, Sugii S, et al: CerS2 haploinsufficiency inhibits $\beta$-oxidation and confers susceptibility to diet-induced steatohepatitis and insulin resistance. Cell Metab 20: 919, 2014.

17. Park WJ, Park JW, Merrill AH, Storch J, Pewzner-Jung Y and Futerman AH: Hepatic fatty acid uptake is regulated by the sphingolipid acyl chain length. Biochim Biophys Acta 1841: 1754-1766, 2014 
18. Maceyka M, Harikumar KB, Milstien S and Spiegel S: Sphingosine-1-phosphate signaling and its role in disease. Trends Cell Biol 22: 50-60, 2012.

19. Strub GM, Maceyka M, Hait NC, Milstien S and Spiegel S: Extracellular and intracellular actions of sphingosine-1phosphate. Adv Exp Med Biol 688: 141-155, 2010.

20. Nagahashi M, Tsuchida J, Moro K, Hasegawa M, Tatsuda K, Woelfel IA, Takabe K and Wakai T: High levels of sphingolipids in human breast cancer. J Surg Res 204: 435-444, 2016.

21. Erez-Roman R, Pienik R and Futerman AH: Increased ceramide synthase 2 and 6 mRNA levels in breast cancer tissues and correlation with sphingosine kinase expression. Biochem Biophys Res Commun 391: 219-223, 2010.

22. Fan S, Niu Y, Tan N, Wu Z, Wang Y, You H, Ke R, Song J, Shen Q, Wang W, et al: LASS2 enhances chemosensitivity of breast cancer by counteracting acidic tumor microenvironment through inhibiting activity of V-ATPase proton pump. Oncogene 32: 1682-1690, 2013

23. Fan SH, Wang YY, Lu J, Zheng YL, Wu DM, Zhang ZF, Shan Q, Hu B, Li MQ and Cheng W: CERS2 suppresses tumor cell invasion and is associated with decreased V-ATPase and MMP-2/MMP-9 activities in breast cancer. J Cell Biochem 116 502-513, 2015.

24. Fekry B, Esmaeilniakooshkghazi A, Krupenko SA and Krupenko NI: Ceramide synthase 6 is a novel target of methotrexate mediating its antiproliferative effect in a p53-dependent manner. PLoS One 11: e0146618, 2016.

25. Maeng HJ, Song JH, Kim GT, Song YJ, Lee K, Kim JY and Park TS: Celecoxib-mediated activation of endoplasmic reticulum stress induces de novo ceramide biosynthesis and apoptosis in hepatoma HepG2 cells mobilization. BMB Rep 50: 144-149, 2017.

26. Denard B, Lee C and Ye J: Doxorubicin blocks proliferation of cancer cells through proteolytic activation of CREB3L1. Elife 1: e00090, 2012.

27. Mosmann T: Rapid colorimetric assay for cellular growth and survival: Application to proliferation and cytotoxicity assays. J Immunol Methods 65: 55-63, 1983.

28. Cerami E, Gao J, Dogrusoz U, Gross BE, Sumer SO, Aksoy BA, Jacobsen A, Byrne CJ, Heuer ML, Larsson E, et al: The cBio cancer genomics portal: An open platform for exploring multidimensional cancer genomics data. Cancer Discov 2: 401-404 2012.

29. Merrill AH, van Echten G, Wang Eand Sandhoff K: Fumonisin B1 inhibits sphingosine (sphinganine) $\mathrm{N}$-acyltransferase and de novo sphingolipid biosynthesis in cultured neurons in situ. J Biol Chem 268: 27299-27306, 1993

30. Cancer Genome Atlas Network; Koboldt DC, Fulton RS, McLellan MD, Schmidt H, Kalicki-Veizer J, McMichael JF, Fulton LL, Dooling DJ, Ding L, Mardis ER, et al: Comprehensive molecular portraits of human breast tumours. Nature 490: 61-70, 2012 .
31. Woodcock J: Sphingosine and ceramide signalling in apoptosis. IUBMB Life 58: 462-466, 2006.

32. Shayman JA: Sphingolipids. Kidney Int 58: 11-26, 2000.

33. Toss A and Cristofanilli M: Molecular characterization and targeted therapeutic approaches in breast cancer. Breast Cancer Res 17: 60, 2015

34. Mendoza MC, ErEE and Blenis J: The Ras-ERK and PI3K-mTOR pathways: Cross-talk and compensation. Trends Biochem Sci 36: 320-328, 2011.

35. Serra V, Scaltriti M, Prudkin L, Eichhorn PJ, Ibrahim YH, Chandarlapaty S, Markman B, Rodriguez O, Guzman M, Rodriguez S, et al: PI3K inhibition results in enhanced HER signaling and acquired ERK dependency in HER2-overexpressing breast cancer. Oncogene 30: 2547-2557, 2011.

36. Baselga J, Campone M, Piccart M, Burris HA III, Rugo HS, Sahmoud T, Noguchi S, Gnant M, Pritchard KI, Lebrun F, et al: Everolimus in postmenopausal hormone-receptor-positive advanced breast cancer. N Engl J Med 366: 520-529, 2012.

37. Piccart M, Hortobagyi GN, Campone M, Pritchard KI, Lebrun F, Ito Y, Noguchi S, Perez A, Rugo HS, Deleu I, et al: Everolimus plus exemestane for hormone-receptor-positive, human epidermal growth factor receptor-2-negative advanced breast cancer: Overall survival results from BOLERO-2†. Ann Oncol 25: 2357-2362, 2014.

38. Min J, Mesika A, Sivaguru M, Van Veldhoven PP, Alexander H, Futerman AH and Alexander S: (Dihydro)ceramide synthase 1 regulated sensitivity to cisplatin is associated with the activation of p38 mitogen-activated protein kinase and is abrogated by sphingosine kinase 1. Mol Cancer Res 5: 801-812, 2007.

39. Blaho VA and Hla T: An update on the biology of sphingosine 1-phosphate receptors. J Lipid Res 55: 1596-1608, 2014.

40. Schiffmann S, Sandner J, Birod K, Wobst I, Angioni C, Ruckhäberle E, Kaufmann M, Ackermann H, Lötsch J, Schmidt H, et al: Ceramide synthases and ceramide levels are increased in breast cancer tissue. Carcinogenesis 30: 745-752, 2009.

41. Gupta V, Bhinge KN, Hosain SB, Xiong K, Gu X, Shi R, Ho MY, Khoo KH, Li SC, Li YT, et al: Ceramide glycosylation by glucosylceramide synthase selectively maintains the properties of breast cancer stem cells. J Biol Chem 287: 37195-37205, 2012.

42. Novgorodov SA, Chudakova DA, Wheeler BW, Bielawski J, Kindy MS, Obeid LM and Gudz TI: Developmentally regulated ceramide synthase 6 increases mitochondrial $\mathrm{Ca}^{2+}$ loading capacity and promotes apoptosis. J Biol Chem 286: 4644-4658, 2011.

43. Yu J, Novgorodov SA, Chudakova D, Zhu H, Bielawska A, Bielawski J, Obeid LM, Kindy MS and Gudz TI: JNK3 signaling pathway activates ceramide synthase leading to mitochondrial dysfunction. J Biol Chem 282: 25940-25949, 2007. 